\title{
Changing Epidemiology and Control of Clostridium difficile in Older Adults
}

\author{
Natasha Bagdasarian • Krishna Rao • \\ Preeti N. Malani
}

Published online: 1 June 2013

(C) Springer Science+Business Media New York 2013

\begin{abstract}
Clostridium difficile infection (CDI) presents unique clinical challenges among older adults. Older patients tend to have more severe disease, more treatment failures, and higher rates of relapse. As the burden of CDI in older adults continues to grow, better paradigms for the prevention and treatment of CDI in this vulnerable population will be essential. In this review, we offer an overview of the changing epidemiology of $C$. difficile, with a review of CDI prevention, diagnosis and treatment, with a focus on older patients.
\end{abstract}

Keywords Elderly · Aged · Clostridium difficile .

Diarrhea $\cdot$ Infection

N. Bagdasarian

Departments of Medical Education and Internal Medicine,

Division of Infectious Diseases, Oakwood Healthcare System,

Dearborn, MI, USA

K. Rao $\cdot$ P. N. Malani

Department of Internal Medicine, Division of Infectious Diseases, University of Michigan Medical School, University of Michigan Health System, Ann Arbor, MI, USA

P. N. Malani

Geriatric and Palliative Medicine, University of Michigan Health System, Ann Arbor, MI, USA

P. N. Malani

Geriatric Research Education and Clinical Center (GRECC),

Veterans Affairs Ann Arbor Healthcare System, Ann Arbor, MI, USA

N. Bagdasarian $(\bowtie)$

Medical Education, Oakwood Hospital and Medical Center, 18101

Oakwood Blvd,

Dearborn, MI 48124, USA

e-mail: natasha.bagdasarian@oakwood.org

\section{Introduction}

Although Clostridium difficile was first identified as the major cause of antibiotic-associated diarrhea in the 1970 s, more recently $C$. difficile infection (CDI) has emerged as a more frequent, more severe and more difficult to manage clinical entity, especially among older adults [1]. C. difficile infection is linked to increased hospital costs and length of stay, and the cost of CDI in the United States is estimated at $\$ 1.1$ billion per year [2]. The burgeoning CDI problem is related in large part to healthcare associated spread of $C$. difficile, especially among the elderly [3]. Targeted measures to curtail CDI in this vulnerable population remain essential.

\section{The Changing Epidemiology of $C$. difficile}

During the past decade, increases in the incidence and severity of CDI have been reported across the United States, Canada, and Europe, with patients over the age of 65 affected disproportionately [3-7]. In the U.S., hospital discharges listing a diagnosis of CDI doubled between 1996 and 2003 [3]. The increase in severity of CDI has been closely linked to the emergence of the epidemic BI/NAP1 strain of $C$. difficile $[4,6]$, but may also be linked to the increasing age and presence of comorbidities among hospitalized patients, [3].

\section{Risk Factors Associated with $C$. difficile Infection}

Advanced age has repeatedly been identified as a risk factor for the development of CDI [8-10, 11••] and CDI-associated mortality also appears to increase with age [12]. Two-thirds of all patients discharged from a U.S. hospital with a diagnosis of CDI are over the age of 65 years [13]. 
Other factors associated with an increased risk of CDI include previous hospitalization, increased duration of hospitalization, non-surgical admission, use of broad spectrum or multiple antibiotics, duration of antibiotic use, use of acid suppressive therapy, receipt of chemotherapy, renal insufficiency or hemodialysis, and presence of a nasogastric tube $[9,14-17]$. Healthcare associated transmission of $C$. difficile is a significant issue, and patients residing in a room previously occupied by a CDI-positive patient, or in a room adjacent to a patient with CDI, are also at greater risk of CDI $[10,18]$.

The risk of developing CDI does not disappear following discharge of older patients from the acute care setting, and one recent study found that, $50 \%$ of CDI cases in long-term care facilities (LTCF) occurred more than four weeks following hospital-discharge, underscoring the need for CDI prevention to remain a priority in the LTCF setting [19]. Cases of CDI may also be diagnosed in the outpatient setting, although previous hospital stay remains a significant risk factor [20].

\section{Outcomes in Older Adults}

C. difficile infection is associated with an increase in 30-day mortality among hospitalized patients, and older adults with CDI tend to have worse outcomes than their younger counterparts [21]. One report suggests that half of all patients in intensive care units (ICU) with CDI are 65 years of age or older, and that their 30-day mortality is two-thirds higher than in younger patients [22••].

Factors associated with worse outcomes among older patients with CDI include infection with the BI epidemic strain, renal insufficiency, leukocytosis and hypoalbuminemia $[17,21,23 \cdot]$. Prolonged exposure to antimicrobials (other than those for the treatment of CDI) is also associated with adverse clinical outcomes, including increased mortality [24].

Readmission following an episode of CDI is a significant problem among older adults. One report suggests that for hospital admissions where CDI is the principle diagnosis, 30day readmission rates are $5.5 \%$ for patients 65 years and older, compared to rates of $3.3 \%$ for patients aged 18-44 years [25]. Recurrent episodes of CDI are also a common phenomenon in older adults, and risk of recurrence rises with age [26•]. One recent study described lower rates of clinical cure, greater risk of recurrence, and lower sustained clinical response associated with advancing decade after the age of 40 years [23•].

\section{Diagnosis}

A case of CDI is defined by a positive stool sample (either assay for toxins $\mathrm{A} / \mathrm{B}$, culture or other means), or by endoscopic or histopathologic evidence of pseudomembranous colitis, in a symptomatic patient $[27,28]$. C. difficile-associated diarrhea, may be defined as three or more episodes of loose stool per day, for two or more days [29]. Testing for $C$. difficile should be performed only on unformed stool, unless $C$. difficile-associated ileus is suspected [28].

While there is not a gold standard test for detection of $C$. difficile, both cell culture cytotoxicity neutralization assay (CCNA) and toxigenic culture are highly sensitive and specific, although not frequently used in clinical laboratories [30-32]. C. difficile toxin detection enzyme immunoassays (CDT-EIA) were, for many years, the main testing strategy at the great majority of clinical laboratories in the U.S. [32]. However, these CDT-EIAs demonstrate highly variable sensitivity (69-99 \%) with low positive predictive values (PPVs) (less than $50 \%$ in some reports) when the prevalence of CDI is relatively low [33]. In fact, CDT-EIA testing alone can yield false positives at a rate of $10-20 \%$ compared to cell cytotoxicity assay, with variability attributed to inaccuracies in the specific test used [34].

Many clinical laboratories now utilize two-stage testing strategies; combining highly sensitive rapid screening tests, either CDT-EIAs and/or glutamate dehydrogenase antigen enzyme immunoassays (GDH-EIA), with a more specific confirmatory test, such as Nucleic acid amplification testing (NAAT) [34-36] [31]. NAAT for the gene responsible for toxin B production (tcdB) improves specificity for toxigenic C. difficile to $94 \%$, but does not directly detect free toxin [34]. Meanwhile, a two-step algorithm, coupling GDH-EIA and CDT-EIA, followed by NAAT for tcdB in samples with discordant EIA results, can minimize the weaknesses inherent in each modality [37].

Several key issues make diagnostic testing for recurrent CDI difficult to interpret. The natural history of clinical recovery from CDI includes prolonged shedding of the organism in stool. The duration of asymptomatic shedding varies, but up to $50 \%$ of patients have positive stool assays six weeks after the completion of therapy $[38,39]$. Long-term colonization can also occur after a successfully-treated episode of CDI [40]. During the early recovery period, recurrent symptoms can occur from a transient functional bowel disorder (FBD) in as many as $35 \%$ of patients, and rarely this can lead to a persistent postinfectious irritable bowel syndrome (IBS) [41]. It is important to distinguish between symptoms due to recurrent CDI and another cause such as FBD or IBS, as current guidelines advise against treatment of asymptomatic carriage / shedding [42]. Given these issues, testing of stool from asymptomatic patients, and "tests of cure" are not clinically useful and are not recommended [28].

Unfortunately, with the use of currently available diagnostic tests it may be difficult to distinguish asymptomatic shedding from symptomatic CDI. Proper identification of actual CDI requires integrating the clinical presentation and symptoms with testing results. Decisions regarding treatment in this setting are thus left to the individual clinician. 


\section{Treatment}

Medications for the Treatment of CDI

The approach to the treatment of CDI in older adults presents unique challenges. When selecting a treatment regimen, clinicians should be mindful that older patients have more severe disease, more treatment failures and a higher relapse rate.

Treatment of CDI is recommended for symptomatic patients only; asymptomatic carriers of $C$. difficile do not require treatment with antimicrobials, and prophylactic therapy for those at high risk of CDI is also not recommended $[27,28,43,44]$. In fact, there is some suggestion that asymptomatic colonization with $C$. difficile may decrease the risk of developing symptomatic CDI [45].

Virtually all antibiotics are associated with increased risk of developing CDI [46]. For symptomatic patients receiving antimicrobial therapy at the time of diagnosis of CDI, removal of the precipitating agent may allow for repopulation of the colon with normal flora, although this is usually not sufficient for treatment. However, if the indication to continue antimicrobials is not clear, it is prudent to stop the offending agent(s).

Metronidazole is the primary first-line therapy for the treatment of mild to moderate, uncomplicated CDI [28]. Early studies indicated that oral metronidazole and oral vancomycin had equivalent efficacy for the treatment of CDI, similar rates of relapse and with similar tolerability [47, 48]. However, gastrointestinal complaints are common among patients taking metronidazole, including reports of a metallic taste, and prolonged, high-dose, metronidazole has been associated with symptoms of peripheral neuropathy, which can rarely persist for up to two-years after use [49].

Vancomycin has emerged as the preferred agent in patients with severe CDI (markers for severe disease include fever, leukocytosis with a white blood cell count (WBC) of 15,000 cells $/ \mu \mathrm{L}$ or higher, or a serum creatinine level greater than or equal to 1.5 times the baseline level) [28, 50-52]. Oral or rectal administration of vancomycin plus intravenous metronidazole, are often used in combination, in cases of severe, complicated CDI [28].

Fidaxomicin is the newest drug approved for the treatment of CDI. Similar rates of clinical cure have been seen with fidaxomicin compared to vancomycin, although there is some data to suggest lower risk of recurrence with fidaxomicin; a $60 \%$ lower risk of recurrence in one study, and better rates of clinical cure in the presence of concomitant antibiotics [23•, 53-56]. There is limited data on other adjunctive therapies for the treatment of CDI, including nitazoxanide and rifaximin, and these agents will not be discussed in detail here.
Complicated CDI

Fulminant CDI is characterized by abdominal pain, fever, hypotension, tachypnea, lactic acidosis and significant leukocytosis (WBC count of $>20,000$ cells $/ \mathrm{mm} 3$ ) and can result in serious complications, including bowel perforation, megacolon, and death [57, 58]. Prompt surgical evaluation should be undertaken in any patient with these signs or symptoms, as emergent colectomy can be lifesaving in these patients. A new surgical approach for treatment of fulminant CDI has become popular: loop ileostomy followed by antegrade vancomycin enemas. This approach is potentially life-saving and also can avoid a total colectomy-a recent study achieved preservation of the colon in $93 \%$ of patients treated this way [59]. Among older adults with fulminant CDI, factors associated with increased 30-day mortality include age over 75 years, lack of leukocytosis, and development of septic shock [22••].

Elderly patients with CDI experience a higher rate of relapse, as well as more treatment failures on standard therapy [60-62]. Treatment failures may be due to the kinetics of toxin production, and the inability to get effective levels of drug to the colon before toxin has bound [63, 64]. Increasing minimum inhibitory concentration (MIC) values for metronidazole have been observed in some strains, however this does not seem to be an issue with vancomycin [64].

Recurrent CDI is a particular problem in older adults $[23 \cdot, 26 \bullet, 60]$. Lower concentrations of antibodies to toxins $\mathrm{A}$ and $\mathrm{B}$, after an episode of CDI, have been associated with risk of recurrence $[65,66]$, and immunosenescence in older adults may be related to their increased risk of recurrent CDI. Recurrent CDI is sometimes treated with extended courses of therapy, adjunctive antimicrobials, which will not be addressed here, or fecal microbiota transplantation (FMT), which is addressed below.

\section{Human Gut Microbiota, Probiotics and Fecal Microbiota Transplantation}

The human gut microbiota is a diverse ecosystem with at least 300-500 species of bacteria [67], which is thought to be protective against invasion by pathogens. Figure 1 illustrates the pathogenesis of CDI: broad-spectrum antibiotics alter the microbiota into a susceptible state, $C$. difficile is introduced, and CDI ensues. Following infection in some individuals, the gut microbiota remains susceptible and recurrent CDI can occur, either as a relapse from the same strain or reinfection from another strain, and may ultimately lead to further recurrent episodes of CDI, refractory to traditional approaches to therapy [68].

Probiotics are live microorganisms which, when administered in adequate doses, can assist in restoring the normal colonic microbiota, which is an essential aspect of preventing 


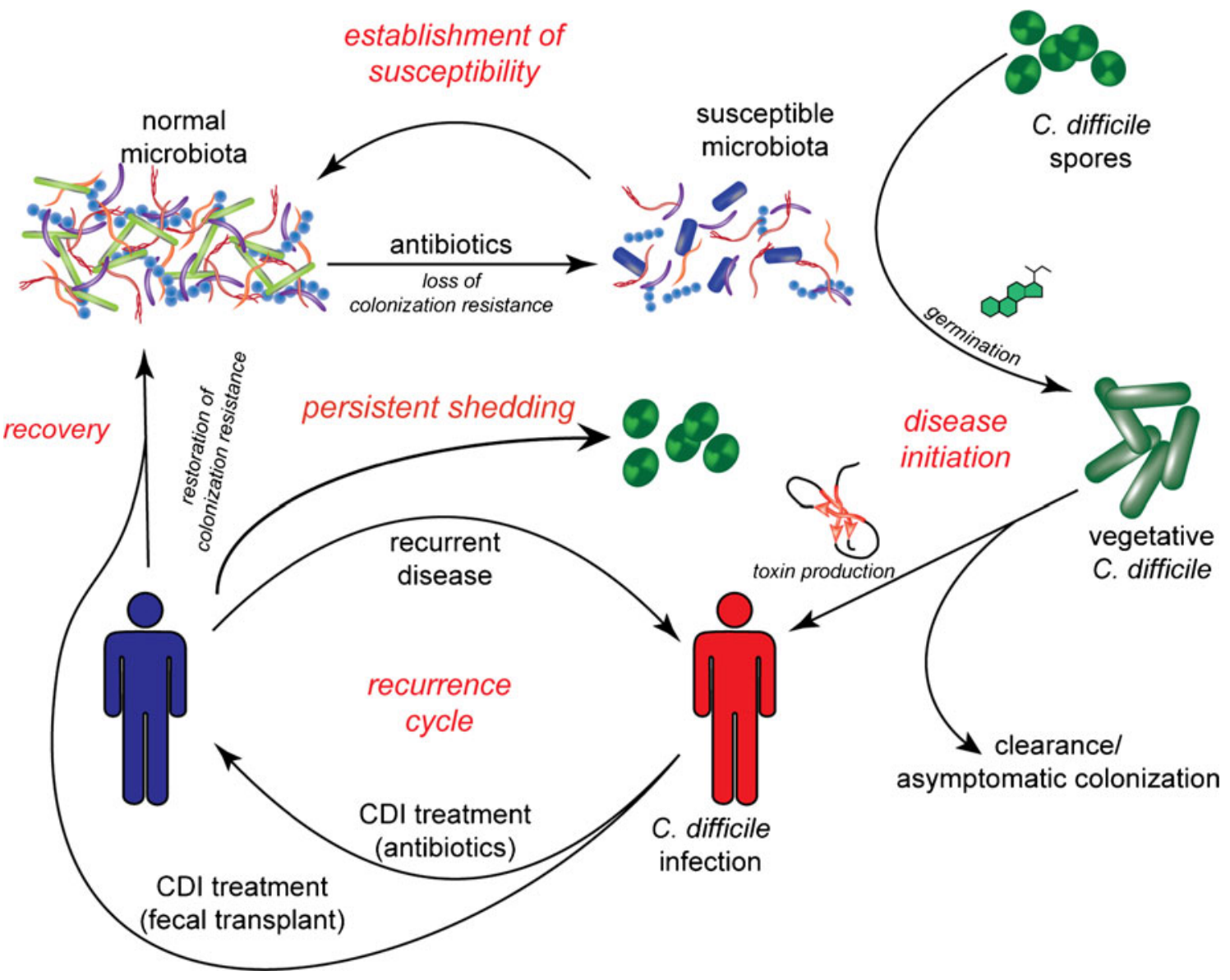

Fig. 1 Pathogenesis of Clostridium difficile infection (CDI). This figure illustrates how the normal microbiota (upper left corner) is altered by antibiotics to a susceptible state in which CDI can occur. It also shows the cycle of recurrence that occurs in some individuals and how, even after successful treatment of CDI, persistent shedding can occur. (Figure courtesy of Vincent B. Young, MD, PhD)
CDI recurrence [69]. While the role of probiotics in the treatment of CDI has not been well-defined, one double-blind, placebo-controlled trial reported that therapy with high-dose oral vancomycin plus a probiotic (Saccharomyces boulardii) was $67 \%$ more effective in preventing CDI recurrences than vancomycin alone [70]. There have been reports of fungemia associated with probiotic use [69], but probiotics are generally well tolerated without major side effects [71].

Fecal microbiota transplantation (FMT) similarly restores colonic microbiota to a healthy state, by transplanting healthy donor stool into an infected patient, and is emerging as a promising solution to this recalcitrant problem. Fecal microbiota transplantation was first performed successfully for CDI treatment in 1983, via rectal enema [72], however the procedure received slow acceptance. Since then, numerous case reports and case series have been published. A large systematic review by Gough et al. [73] included published articles, abstracts, as well as unpublished data, on 317 patients with recurrent CDI. The routes used for FMT in this review included rectal enema (35\%), Nasojejunal tube/gastroscope (23\%), and colonoscopy (42\%). Despite significant variability between reports regarding FMT infusion site, amount of donor stool, and donor stool preparation, the results were resounding; $92 \%$ of patients had resolution of their recurrent $\mathrm{CDI}$, with $89 \%$ resolution after a single treatment. Of the $4 \%$ of patients who had relapsed CDI after initial FMT, $87.5 \%$ had resolution with repeat FMT. There were no serious adverse effects directly attributable to FMT, but symptoms of an irritable colon (constipation, diarrhea, cramping, bloating) were reported shortly after FMT and were usually transient. Since this systematic review, several additional case series have been published describing FMT via colonoscopy [74, 75] and rectal enema [76], with similar success rates of 86 $93 \%$. One study used a standard frozen preparation for FMT from a single universal donor for the majority of cases [75].

While case reports and case series have been encouraging, there was a lack of high quality data in field of FMT, until recently. In 2013 van Nood and colleagues published a randomized controlled trial for FMT via duodenal infusion for recurrent CDI [77]. Patients were randomized to receive vancomycin for 5 days followed by FMT $(n=16)$, vancomycin alone for 14 days $(n=13)$, or vancomycin for 14 days 
with bowel lavage (rapid administration of a large volume of polyethylene glycol solution) $(n=13)$. The primary outcome was cure defined as absence of diarrhea or persistent diarrhea from another cause with three consecutive negative stool tests for $C$. difficile toxin. The study was stopped early after an interim analysis, as $94 \%$ of patients in the FMT group achieved cure, most of those after only one infusion, versus $31 \%$ in the vancomycin alone or vancomycin with bowel lavage groups, respectively. Based on these findings, off-protocol FMT was offered to 18 patients in the other treatment arms and this achieved an $83 \%$ cure rate. Although further study is needed to fully ascertain the safety and efficacy of FMT for recurrent CDI, it shows promise as an excellent treatment for this difficult disease.

The regulatory status of FMT in the United States was previously ill-defined, but currently the FDA is requiring that any center wanting to perform FMT must apply for an expanded access IND as described in the code of federal regulations: 21 CFR 312 Subpart I [21 CFR 312.300].

\section{Prevention of Healthcare Associated Transmission of CDI}

C. difficile is a common environmental contaminant in healthcare facilities, including nursing homes, and there is a strong association between the level of environmental contamination and healthcare associated transmission [78]. Spores can survive on hard surfaces for up to five months, and have been found on the floors, toilets, bedding and furniture in rooms of patients with CDI [79].

Strategies to reduce patient exposure to $C$. difficile (contact precautions, environmental cleaning, hand hygiene) and strategies to prevent alteration of the normal fecal microbiota (antimicrobial stewardship) are vital to prevent CDI. These strategies are often implemented as part of infection control bundles [80, 81]. Current SHEA/IDSA guidelines recommend the following to prevent the spread of CDI: private rooms when possible for patients with CDI, barrier precautions for patients with CDI (gowns and gloves), emphasis on hand hygiene with soap and water, and environmental decontamination of rooms with a 1:10 sodium hypochlorite solution $[27,28]$. The use of barrier precautions for patients with asymptomatic colonization of $C$. difficile is not generally recommended $[27,28]$. Some of these precautions may be difficult to implement in the LTCF setting.

C. difficile has been isolated from the hands of asymptomatic healthcare workers, and transmission by healthcare workers is likely an important source of nosocomial spread [79]. Alcoholbased hand rubs (ABHR) have activity against the vegetative form of $C$. difficile, but are not sporicidal, although this deficit may be offset by improved hand hygiene compliance seen with the use of ABHR. Some evidence suggests that hand hygiene adherence improves dramatically when alcohol-based hand cleansers are available, without significantly impacting rates of CDI [82-84].

\section{Antimicrobial Stewardship}

Antibiotic use is the strongest risk factor for the development of CDI, especially with multiple agents, or prolonged use, although virtually all antibiotics can precipitate CDI [46]. An Antimicrobial Stewardship Program (ASP) can help to reduce rates of CDI by establishing guidelines and clinical pathways for prudent antimicrobial use, deescalating therapy when possible, optimizing dosing and reducing duration of treatment [85].

\section{Conclusion}

As CDI has increased in frequency and severity in the U.S. and many other parts of the world, older adults have been disproportionately affected. Older patients tend to have more severe disease, more treatment failures and a higher relapse rate. As the population ages, elderly patients will continue to be at risk of CDI acquisition in both the acute care and long term care setting. Thoughtful approaches to prevention and treatment will remain essential.

Acknowledgements This work was supported in part by the National Institutes of Health grant 1U19AI090871-01 (K. R and P. N. M.) and the Department of Veterans Affairs and Geriatric Research Education and Clinical Center (P. N. M).

\section{Compliance with Ethics Guidelines}

Conflict of Interest Natasha Bagdasarian, Krishna Rao, and Preeti $\mathrm{N}$. Malani declare that they have no conflict of interest.

Human and Animal Rights and Informed Consent This article does not contain any studies with human or animal subjects performed by any of the authors.

\section{References}

Papers of particular interest, published recently, have been highlighted as:

- Of importance

-. Of major importance

1. Bartlett JG. Narrative review: the new epidemic of Clostridium difficile-associated enteric disease. Ann Intern Med. 2006;145(10): 758-64. 
2. Kyne L, Hamel MB, Polavaram R, et al. Health care costs and mortality associated with nosocomial diarrhea due to Clostridium difficile. Clin Infect Dis. 2002;34(3):346-53.

3. McDonald LC, Owings M, Jernigan DB. Clostridium difficile infection in patients discharged from US short-stay hospitals, 1996-2003. Emerg Infect Dis. 2006;12(3):409-15.

4. Dubberke ER, Wertheimer AI. Review of current literature on the economic burden of Clostridium difficile infection. Infect Control Hosp Epidemiol. 2009;30(1):57-66.

5. Akerlund T, Persson I, Unemo M, et al. Increased sporulation rate of epidemic Clostridium difficile type 027/NAP1. J Clin Microbiol. 2008;46(4):1530-3.

6. McDonald LC, Killgore GE, Thompson A, et al. An epidemic, toxin gene-variant strain of Clostridium difficile. N Engl J Med. 2005;353(23):2433-41

7. Pepin J, Valiquette L, Alary ME, et al. Clostridium difficileassociated diarrhea in a region of Quebec from 1991 to 2003: a changing pattern of disease severity. CMAJ. 2004;171(5):466-72.

8. Dubberke ER, Reske KA, Yan Y, et al. Clostridium difficileassociated disease in a setting of endemicity: identification of novel risk factors. Clin Infect Dis. 2007;45(12):1543-9.

9. Garey KW, Dao-Tran TK, Jiang ZD, et al. A clinical risk index for Clostridium difficile infection in hospitalised patients receiving broad-spectrum antibiotics. J Hosp Infect. 2008;70(2):142-7.

10. Howitt JR, Grace JW, Schaefer MG, et al. Clostridium difficilepositive stools: a retrospective identification of risk factors. Am J Infect Control. 2008;36(7):488-91.

11. • Henrich TJ, Krakower D, Bitton A, et al. Clinical risk factors for severe Clostridium difficile-associated disease. Emerg Infect Dis. 2009;15(3):415-22. Retrospective review identifying factors associated with severe CDI, including age $>70$ years.

12. Loo VG, Poirier L, Miller MA, et al. A predominantly clonal multi-institutional outbreak of Clostridium difficile-associated diarrhea with high morbidity and mortality. N Engl J Med. 2005;353(23):2442-9.

13. Zilberberg MD, Shorr AF, Kollef MH. Increase in adult Clostridium difficile-related hospitalizations and case-fatality rate, United States, 2000-2005. Emerg Infect Dis. 2008;14(6):929-31.

14. Brown E, Talbot GH, Axelrod P, et al. Risk factors for Clostridium difficile toxin-associated diarrhea. Infect Control Hosp Epidemiol. 1990;11(6):283-90.

15. McFarland LV, Surawicz CM, Stamm WE. Risk factors for Clostridium difficile carriage and C. difficile-associated diarrhea in a cohort of hospitalized patients. J Infect Dis. 1990;162(3): 678-84.

16. Aseeri M, Schroeder T, Kramer J, et al. Gastric acid suppression by proton pump inhibitors as a risk factor for clostridium difficileassociated diarrhea in hospitalized patients. Am J Gastroenterol. 2008;103(9):2308-13.

17. Keddis MT, Khanna S, Noheria A, et al. Clostridium difficile infection in patients with chronic kidney disease. Mayo Clin Proc. 2012;87(11):1046-53.

18. Shaughnessy MK, Micielli RL, DePestel DD, et al. Evaluation of hospital room assignment and acquisition of Clostridium difficile infection. Infect Control Hosp Epidemiol. 2011;32(3):201-6.

19. Pawar D, Tsay R, Nelson DS, et al. Burden of Clostridium difficile infection in long-term care facilities in Monroe County, New York. Infect Control Hosp Epidemiol. 2012;33(11):1107-12.

20. Kuntz JL, Johnson ES, Raebel MA, et al. Epidemiology and healthcare costs of incident Clostridium difficile infections identified in the outpatient healthcare setting. Infect Control Hosp Epidemiol. 2012;33(10):1031-8.

21. Hensgens MP, Goorhuis A, Dekkers OM, et al. All-cause and disease-specific mortality in hospitalized patients with Clostridium difficile infection: a multicenter cohort study. Clin Infect Dis. 2013;56(8):1108-16.
22. • Zilberberg MD, Shorr AF, Micek ST, et al. Clostridium difficileassociated disease and mortality among the elderly critically ill. Crit Care Med. 2009 Jul 20. Retrospective review comparing characteristics and outcomes of the elderly vs. the younger groups, and elderly 30-day survivors with nonsurvivors.

23. - Louie TJ, Miller MA, Crook DW, et al. Effect of age on treatment outcomes in Clostridium difficile infection. J Am Geriatr Soc. 2013;61(2):222-30. Randomized trial comparing vancomycin to fidaxomicin to examine the effects of age and study drug on outcomes of cure, and recurrence.

24. Pop-Vicas A, Shaban E, Letourneau C, et al. Empirical antimicrobial prescriptions in patients with Clostridium difficile infection at hospital admission and impact on clinical outcome. Infect Control Hosp Epidemiol. 2012;33(11):1101-6.

25. Elixhauser A, Steiner C, Gould C. Readmissions following hospitalizations with clostridium difficile infections, 2009: statistical brief \#145. 2006 Feb.

26. - Eyre DW, Walker AS, Wyllie D, et al. Predictors of first recurrence of Clostridium difficile infection: implications for initial management. Clin Infect Dis. 2012;55 Suppl 2:S77-87. Evaluated risk of recurrence in 1678 adults after their first episode of CDI; identified factors such as increasing age, initial disease severity, and hospital exposure.

27. Dubberke ER, Gerding DN, Classen D, et al. Strategies to prevent clostridium difficile infections in acute care hospitals. Infect Control Hosp Epidemiol. 2008;29 Suppl 1:S81-92.

28. Cohen SH, Gerding DN, Johnson S, et al. Clinical practice guidelines for Clostridium difficile infection in adults: 2010 update by the society for healthcare epidemiology of America (SHEA) and the infectious diseases society of America (IDSA). Infect Control Hosp Epidemiol. 2010;31(5):431-55.

29. Kyne L, Merry C, O'Connell B, et al. Factors associated with prolonged symptoms and severe disease due to Clostridium difficile. Age Ageing. 1999;28(2):107-13.

30. Wilkins TD, Lyerly DM. Clostridium difficile testing: after 20 years, still challenging. J Clin Microbiol. 2003;41(2):5314.

31. Stamper PD, Alcabasa R, Aird D, et al. Comparison of a commercial real-time PCR assay for tcdB detection to a cell culture cytotoxicity assay and toxigenic culture for direct detection of toxin-producing Clostridium difficile in clinical samples. J Clin Microbiol. 2009;47(2):373-8.

32. Bartlett JG, Gerding DN. Clinical recognition and diagnosis of Clostridium difficile infection. Clin Infect Dis. 2008;46 Suppl $1:$ S12-8.

33. Planche T, Aghaizu A, Holliman R, et al. Diagnosis of Clostridium difficile infection by toxin detection kits: a systematic review. Lancet Infect Dis. 2008;8(12):777-84.

34. Wilcox M. Overcoming barriers to effective recognition and diagnosis of Clostridium difficile infection. Clin Microbiol Infect. 2012;18(s6):13-20.

35. Ticehurst JR, Aird DZ, Dam LM, et al. Effective detection of toxigenic Clostridium difficile by a two-step algorithm including tests for antigen and cytotoxin. J Clin Microbiol. 2006;44(3):1145-9.

36. Fenner L, Widmer AF, Goy G, et al. Rapid and reliable diagnostic algorithm for detection of Clostridium difficile. J Clin Microbiol. 2008;46(1):328-30.

37. Wilcox MH. Overcoming barriers to effective recognition and diagnosis of Clostridium difficile infection. Clin Microbiol Infect. 2012;18 Suppl 6:13-20.

38. Fekety R, Silva J, Kauffman C, et al. Treatment of antibioticassociated Clostridium difficile colitis with oral vancomycin: comparison of two dosage regimens. Am J Med. 1989;86(1):15-9.

39. McFarland LV, Elmer GW, Surawicz CM. Breaking the cycle: treatment strategies for 163 cases of recurrent Clostridium difficile disease. Am J Gastroenterol. 2002;97(7):1769-75. 
40. Sethi Ajay K, Al-Nassir Wafa N, Nerandzic Michelle M, et al. Persistence of skin contamination and environmental shedding of Clostridium difficile during and after treatment of $C$. difficile infection. Infect Control Hosp Epidemiol. 2010;31(1):21-7.

41. Piche T, Vanbiervliet G, Pipau FG, et al. Low risk of irritable bowel syndrome after Clostridium difficile infection. Can J Gastroenterol. 2007;21(11):727-31.

42. Cohen SH, Gerding DN, Johnson S, et al. Clinical practice guidelines for Clostridium difficile infection in adults: 2010 update by the society for healthcare epidemiology of America (SHEA) and the infectious diseases society of America (IDSA). Infect Control Hosp Epidemiol. 2010;31(5):431-55 [Practice Guideline Research Support, Non-U.S. Gov't].

43. Ryan J, Murphy C, Twomey C, et al. Asymptomatic carriage of Clostridium difficile in an Irish continuing care institution for the elderly: prevalence and characteristics. Ir J Med Sci. 2009 Jun 4.

44. Simor AE, Bradley SF, Strausbaugh LJ, et al. Clostridium difficile in long-term-care facilities for the elderly. Infect Control Hosp Epidemiol. 2002;23(11):696-703.

45. Gerding DN, Muto CA, Owens Jr RC. Measures to control and prevent Clostridium difficile infection. Clin Infect Dis. 2008;46 Suppl 1:S43-9.

46. Owens Jr RC, Donskey CJ, Gaynes RP, et al. Antimicrobialassociated risk factors for Clostridium difficile infection. Clin Infect Dis. 2008;46 Suppl 1:S19-31.

47. Olson MM, Shanholtzer CJ, Lee Jr JT, et al. Ten years of prospective Clostridium difficile-associated disease surveillance and treatment at the Minneapolis VA Medical Center, 1982-1991. Infect Control Hosp Epidemiol. 1994;15(6):371-81.

48. Teasley DG, Gerding DN, Olson MM, et al. Prospective randomised trial of metronidazole versus vancomycin for Clostridiumdifficile-associated diarrhoea and colitis. Lancet. 1983;2(8358): 1043-6.

49. Horlen CK, Seifert CF, Malouf CS. Toxic metronidazole-induced MRI changes. Ann Pharmacother. 2000;34(11):1273-5.

50. Zar FA, Bakkanagari SR, Moorthi KM, et al. A comparison of vancomycin and metronidazole for the treatment of Clostridium difficile-associated diarrhea, stratified by disease severity. Clin Infect Dis. 2007;45(3):302-7.

51. Gerding DN. Metronidazole for Clostridium difficile-associated disease: is it okay for mom? Clin Infect Dis. 2005;40(11):1598-600.

52. Bartlett JG. The case for vancomycin as the preferred drug for treatment of Clostridium difficile infection. Clin Infect Dis. 2008;46(10):1489-92.

53. Cornely OA, Crook DW, Esposito R, et al. Fidaxomicin versus vancomycin for infection with Clostridium difficile in Europe, Canada, and the USA: a double-blind, non-inferiority, randomised controlled trial. Lancet Infect Dis. 2012;12(4):281-9.

54. Cornely OA, Miller MA, Louie TJ, et al. Treatment of first recurrence of Clostridium difficile infection: fidaxomicin versus vancomycin. Clin Infect Dis. 2012;55 Suppl 2:S154-61.

55. Mullane KM, Miller MA, Weiss K, et al. Efficacy of fidaxomicin versus vancomycin as therapy for Clostridium difficile infection in individuals taking concomitant antibiotics for other concurrent infections. Clin Infect Dis. 2011;53(5):440-7.

56. Louie TJ, Miller MA, Mullane KM, et al. Fidaxomicin versus vancomycin for Clostridium difficile infection. N Engl J Med. 2011;364(5):422-31.

57. Jaber MR, Olafsson S, Fung WL, et al. Clinical review of the management of fulminant clostridium difficile infection. Am J Gastroenterol. 2008;103(12):3195-203. quiz 204.

58. Lamontagne F, Labbe AC, Haeck O, et al. Impact of emergency colectomy on survival of patients with fulminant Clostridium difficile colitis during an epidemic caused by a hypervirulent strain. Ann Surg. 2007;245(2):267-72.
59. Neal MD, Alverdy JC, Hall DE, et al. Diverting loop ileostomy and colonic lavage: an alternative to total abdominal colectomy for the treatment of severe, complicated Clostridium difficile associated disease. Ann Surg. 2011;254(3):423-7. discussion 79.

60. Garey KW, Sethi S, Yadav Y, et al. Meta-analysis to assess risk factors for recurrent Clostridium difficile infection. J Hosp Infect. 2008;70(4):298-304.

61. Cober ED, Malani PN. Clostridium difficile infection in the "oldest" old: clinical outcomes in patients aged 80 and older. J Am Geriatr Soc. 2009;57(4):659-62.

62. Pepin J, Alary ME, Valiquette L, et al. Increasing risk of relapse after treatment of Clostridium difficile colitis in Quebec, Canada. Clin Infect Dis. 2005;40(11):1591-7.

63. Kelly CP, LaMont JT. Clostridium difficile-more difficult than ever. N Engl J Med. 2008;359(18):1932-40.

64. Brazier JS, Raybould R, Patel B, et al. Distribution and antimicrobial susceptibility patterns of Clostridium difficile PCR ribotypes in English hospitals, 2007-08. Euro Surveill. 2008 Oct 9;13(41).

65. Kyne L, Warny M, Qamar A, et al. Association between antibody response to toxin $\mathrm{A}$ and protection against recurrent Clostridium difficile diarrhoea. Lancet. 2001;357(9251):18993.

66. Leav BA, Blair B, Leney M, et al. Serum anti-toxin B antibody correlates with protection from recurrent Clostridium difficile infection (CDI). Vaccine. 2010;28(4):965-9.

67. Sullivan Å, Edlund C, Nord CE. Effect of antimicrobial agents on the ecological balance of human microflora. Lancet Infect Dis. 2001;1(2):101-14.

68. Figueroa I, Johnson S, Sambol SP, et al. Relapse versus reinfection: recurrent Clostridium difficile infection following treatment with fidaxomicin or vancomycin. Clin Infect Dis. 2012;55 suppl 2:S104-S9.

69. Segarra-Newnham M. Probiotics for Clostridium difficile-associated diarrhea: focus on Lactobacillus rhamnosus GG and Saccharomyces boulardii. Ann Pharmacother. 2007;41(7):1212-21.

70. Surawicz CM, McFarland LV, Greenberg RN, et al. The search for a better treatment for recurrent Clostridium difficile disease: use of high-dose vancomycin combined with Saccharomyces boulardii. Clin Infect Dis. 2000;31(4):1012-7.

71. Safdar N, Barigala R, Said A, et al. Feasibility and tolerability of probiotics for prevention of antibiotic-associated diarrhoea in hospitalized US military veterans. J Clin Pharm Ther. 2008; 33(6):663-8.

72. Schwan A, Sjölin S, Trottestam U. Relapsing Clostridium difficile enterocolitis cured by rectal infusion of homologous faeces. Lancet. 1983;2(8354):845.

73. Gough E, Shaikh H, Manges AR. Systematic review of intestinal microbiota transplantation (fecal bacteriotherapy) for recurrent Clostridium difficile infection. Clin Infect Dis. 2011;53(10):9941002.

74. Kelly CR, de Leon L, Jasutkar N. Fecal microbiota transplantation for relapsing Clostridium difficile infection in 26 patients: methodology and results. J Clin Gastroenterol. 2012;46(2): $145-9$.

75. Hamilton MJ, Weingarden AR, Sadowsky MJ, et al. Standardized frozen preparation for transplantation of fecal microbiota for recurrent Clostridium difficile infection. Am J Gastroenterol. 2012;107(5):761-7.

76. Kassam Z, Hundal R, Marshall JK, et al. Fecal transplant via retention enema for refractory or recurrent Clostridium difficile infection. Arch Intern Med. 2012;172(2):191-3 [Letter].

77. van Nood E, Vrieze A, Nieuwdorp M, et al. Duodenal infusion of donor feces for recurrent Clostridium difficile. N Engl J Med. 2013;368(5):407-15. 
78. Samore MH, Venkataraman L, DeGirolami PC, et al. Clinical and molecular epidemiology of sporadic and clustered cases of nosocomial Clostridium difficile diarrhea. Am J Med. 1996;100(1):32-40.

79. Fekety R, Kim KH, Brown D, et al. Epidemiology of antibioticassociated colitis; isolation of Clostridium difficile from the hospital environment. Am J Med. 1981;70(4):906-8.

80. Muto CA, Blank MK, Marsh JW, et al. Control of an outbreak of infection with the hypervirulent Clostridium difficile BI strain in a university hospital using a comprehensive "bundle" approach. Clin Infect Dis. 2007;45(10):1266-73.

81. Weiss K, Boisvert A, Chagnon M, et al. Multipronged intervention strategy to control an outbreak of Clostridium difficile infection (CDI) and its impact on the rates of CDI from 2002 to 2007. Infect Control Hosp Epidemiol. 2009;30(2):156-62.
82. Vernaz N, Sax H, Pittet D, et al. Temporal effects of antibiotic use and hand rub consumption on the incidence of MRSA and Clostridium difficile. J Antimicrob Chemother. 2008;62(3):601-7.

83. Boyce JM, Ligi C, Kohan C, et al. Lack of association between the increased incidence of Clostridium difficile-associated disease and the increasing use of alcohol-based hand rubs. Infect Control Hosp Epidemiol. 2006;27(5):479-83.

84. Rupp ME, Fitzgerald T, Puumala S, et al. Prospective, controlled, cross-over trial of alcohol-based hand gel in critical care units. Infect Control Hosp Epidemiol. 2008;29(1):8-15.

85. Dellit $\mathrm{TH}$, Owens RC, McGowan Jr JE, et al. Infectious Diseases Society of America and the Society for Healthcare Epidemiology of America guidelines for developing an institutional program to enhance antimicrobial stewardship. Clin Infect Dis. 2007;44(2):159-77. 